\title{
Rising Trends in Ectopic Pregnancy during COVID-19 Pandemic
}

\author{
Surinder Kaur ${ }^{1}$, Preet Kamal ${ }^{2}$, Sangeeta Pahwa ${ }^{3}$, Ripan Bala ${ }^{4}$
}

\begin{abstract}
Introduction: Coronavirus disease-2019 (COVID-19) has spread at an exponential rate in several countries. Whereas understanding of clinical consequences, prevention, and management of COVID-19 is increasing, little is known about the collateral damage caused by it. It is noteworthy that ectopic pregnancies contributed to significant obstetric emergencies in the COVID-19 pandemic and sensitized the caregivers to report the event.

Materials and methods: This retrospective study was conducted at the Tertiary Care Medical and Teaching Institute, Amritsar, India, to observe the rising trends of ectopic pregnancy during the lockdown period from March 22, 2020, to July 30, 2020. Data were taken from the hospital records of Emergency and Gynaecology and Obstetric departments after getting ethical clearance from the ethics committee of the institute. The details of demographic characters, clinical presentation, risk factors, and treatment plan for ectopic pregnancy, as well as associated morbidity and mortality were studied in detail in comparison to times other than during COVID-19 pandemic.

Results: It was observed that the proportion of ruptured ectopic pregnancies was significantly higher during the lockdown period in comparison to the prelockdown period $(12 / 617 ; 1.94 \%$ vs. $17 / 4367 ; 0.381 \%$, Fisher's exact test $p 0.02)$. Majority of patients $(91.66 \%)$ presented late with ruptured ectopic pregnancy with hemoperitoneum and had to undergo emergency laparotomy and a salpingectomy was done in $66.66 \%$ of cases. Discussion: Social lifestyle changes, increased use of emergency contraceptive pills, and medical abortion pills due to poor accessibility of healthcare facilities were observed during this period. Noticeably, a high number of patients came in an emergency with failed medical abortions who were later diagnosed with ruptured ectopic pregnancies.

Conclusion: We think that monitoring the indirect potential consequences of COVID-19 pandemic is imperative in order to avoid unexpected deleterious complications in women's health.

Keywords: COVID-19, Hemoperitoneum, Laparotomy, Medical abortion, Ruptured ectopic pregnancy.

AMEl's Current Trends in Diagnosis \& Treatment (2020): 10.5005/jp-journals-10055-0106
\end{abstract}

\section{INTRODUCTION}

Coronavirus disease-2019 (COVID-19) has spread globally at an exponential rate. Several preventive measures were implemented to reduce its transmissibility. It included restrictions on elective surgical intervention and outpatient visits. The understanding of clinical consequences, prevention, and management of COVID-19 is increasing ${ }_{1}^{1-4}$ but there are certain collateral damages, which are caused by the action taken to limit the spread of the pandemic. The restrictive measures and disruption in healthcare services due to pandemic had deleterious effects on women and children's health. ${ }^{5}$

During the lockdown period, there was a rising trend of spontaneous conceptions, even in subfertile subjects. The social lifestyle changes during lockdown contributed to unwanted pregnancies, even in those couples who were waiting for infertility workup and artificial reproductive techniques (ARTs). The rise in the incidences of ectopic pregnancies during this time is a part of these spontaneous conceptions. A ruptured ectopic pregnancy is the most important cause of maternal mortality and morbidity in the first trimester. ${ }^{6}$

There was an increase in the incidence of use of emergency contraceptive pills and medical abortion pills due to the inaccessibility of healthcare facilities. Noticeably, a high number of patients came in an emergency with failed medical abortion and some of them had actually undiagnosed ectopic pregnancy. Early diagnosis reduces the risk of tubal rupture and allows more conservative medical treatments. ${ }^{7}$
${ }^{1-4}$ Department of Obstetrics and Gynaecology, Sri Guru Ram Das Institute of Medical Sciences and Research, Amritsar, Punjab, India

Corresponding Author: Surinder Kaur, Department of Obstetrics and Gynaecology, Sri Guru Ram Das Institute of Medical Sciences and Research, Amritsar, Punjab, India, Phone: +91 9814065527, e-mail: drsurinderkaur@yahoo.in

How to cite this article: Kaur S, Kamal P, Pahwa S, et al. Rising Trends in Ectopic Pregnancy during COVID-19 Pandemic. AMEl's Curr Trends Diagn Treat 2020;4(2):84-86.

Source of support: Nil

Conflict of interest: None

Although there was a recent trend to diagnose ectopic pregnancy in early stages with an unruptured fallopian tube, due to patients' reluctance to seek medical advice during the lockdown period or due to the reduction of early first trimester scans, the proportion of ruptured ectopic pregnancies was significantly higher.

\section{Materials and Methods}

We conducted a retrospective study at the Tertiary Care Medical and Teaching Institute, Amritsar, India, to observe the rising trends of ectopic pregnancy during the lockdown period from March 22, 2020 , to July 30,2020 . The total number of deliveries was recorded during this period and also from January 2018 to March 2020 from the 
hospital records of Gynaecology and Obstetrics Departments. The details of demographic characters, clinical presentation, risk factors, and treatment plan for ectopic pregnancy, as well as associated morbidity and mortality were studied in detail in comparison to times other than during the COVID-19 pandemic. Among the patients with ectopic pregnancy, the increase in the proportion of women who underwent emergency surgical intervention for a ruptured tubal pregnancy was also evaluated. Emergency surgical intervention was defined as one performed in less than 6 hours after patients' presentation at the hospital. Methotrexate was given as conservative treatment in patients with unruptured tubal pregnancy.

\section{Results}

During the prelockdown period from January 2018 to March 2020, there were 4,367 deliveries in our hospital and during this period, $17(0.38 \%)$ patients with ectopic pregnancy were admitted, whereas during the lockdown period from March 22, 2020, to July 31, 2020, there were 617 deliveries and 12 (1.94\%) ectopic pregnancies were reported (Tables 1 to 4 ).

As shown in Table 1, the majority of patients (50\%) belonged to the age-group of $26-30$ years, which is the age of peak sexual activity and reproduction.

Table 1: Baseline characteristics of study population

\begin{tabular}{lll}
\hline Age (years) & Number of patients & Percentage \\
\hline $20-25$ & 2 & 16.66 \\
$26-30$ & 6 & 50 \\
$>30$ & 4 & 33.34 \\
\hline
\end{tabular}

Table 2: Distribution of patients according to gravidity

\begin{tabular}{llc}
\hline Gravidity & Number of patients & Percentage \\
\hline Primigravida & 4 & 33.33 \\
Second gravida & 1 & 8.33 \\
Third gravida and more & 7 & 58.34 \\
\hline
\end{tabular}

Table 3: Clinical presentation of study population

\begin{tabular}{|c|c|c|c|}
\hline Clinical presentation & $\begin{array}{l}\text { Number of } \\
\text { patients }\end{array}$ & Percentage & $\begin{array}{l}\text { Mode of } \\
\text { treatment }\end{array}$ \\
\hline Mild pain & 2 & 16.67 & $\begin{array}{l}\text { Medical } \\
\text { management }\end{array}$ \\
\hline Severe pain & 2 & 16.67 & Laparotomy \\
\hline Ruptured ectopic pregnancy & 8 & 66.66 & Laparotomy \\
\hline
\end{tabular}

Table 4: Risk factors for ectopic pregnancy in study group

\begin{tabular}{llc}
\hline Risk factors & Number of patients & Percentage \\
\hline $\begin{array}{l}\text { History of (H/o) pelvic } \\
\text { inflammatory disease (PID) }\end{array}$ & 2 & 16.66 \\
$\begin{array}{l}\text { H/o intrauterine contraception } \\
\text { device (IUCD) }\end{array}$ & 1 & 8.33 \\
H/o previous ectopic pregnancy & 1 & \\
H/o medical abortion pill intake & 5 & 8.33 \\
No risk factors & 3 & 41.66 \\
\hline
\end{tabular}

Table 2 depicts that $58.34 \%$ of patients were multigravida and $33.33 \%$ were primigravida. Interestingly, multigravida had more percentages of ectopic pregnancies.

As shown in Table 3, we received twelve patients with ectopic pregnancies, of which eight presented with acute abdomen with hemoperitoneum. Unilateral salpingectomy was the prime procedure done for a ruptured ectopic pregnancy. Two patients were admitted with severe pain with impending rupture. Two patients reported mild pain (in an unruptured state). One patient responded to medical treatment with methotrexate (single dose) and the second patient underwent a laparotomy due to failed medical therapy. Salpingostomy was done in three (25\%) patients who had not completed their family and were hemodynamically stable.

Table 4 shows that in $41.66 \%$ of patients, over-the-counter use of emergency contraceptive pills and medical abortion pills was the contributing factor, whereas $16.66 \%$ of patients had H/o pelvic infection, which may have contributed to peritubal adhesions and impaired tubal motility, leading to ectopic pregnancies.

Laparotomy was done in $91.66 \%$ of patients. In $54.54 \%$ of patients, ectopic pregnancy was in the ampullary region and in $36.36 \%$ the isthmic part of the tube was involved as shown in Table 5.

\section{Statistical Analysis}

In our institute, the total number of deliveries from January 2018 to February 2020 was 4,367, of which $17(0.381 \%)$ patients had ectopic pregnancy, whereas during the lockdown period from March 2020 to July 2020, 12 (1.94\%) patients with ectopic pregnancy were admitted. So, the proportion of ectopic pregnancies was significantly higher during the lockdown period (Fisher's exact test $p=0.02$ ).

\section{Discussion}

Ectopic pregnancies still contribute significantly to obstetric emergencies in the first trimester. In the developed world, 1 to $2 \%$ of all reported pregnancies are ectopic pregnancies. Treatment options include surgery, medical therapy, and observation for a very selective, limited number of patients. ${ }^{8}$

During the lockdown period, probably unevaluated patients with PID with infertility were not adequately managed and possibly this resulted in spontaneous pregnancies but at an extrauterine site. Many patients in the pipeline for ART procedures conceived and had ectopic pregnancies due to tubal factor infertility. The failure of contraception has also been added to the number of ectopic pregnancies.

The majority of women (50\%) in our study belonged to the reproductive age-group of 26 to 30 years, which is close to the study done by Panchal et al. ${ }^{9}$ The majority of women $(66.66 \%)$ were multigravida. The higher incidence may be due to previous miscarriages, resulting in infections, leading to tubal damage.

In the present study, $41.66 \%$ of patients gave a H/O either medical termination of pregnancy kit intake or use of emergency

Table 5: Site of ectopic pregnancy on laparotomy $(n=11)$

\begin{tabular}{llc}
\hline Site of ectopic & Number & Percentage \\
\hline Ampulla & 6 & 54.54 \\
Isthmus & 4 & 36.36 \\
Cornual pregnancy & 1 & 9.10 \\
\hline
\end{tabular}


contraceptive pills. This was probably due to the inaccessibility of healthcare facilities during the lockdown period. PID contributed to $16.66 \%$ of cases. This is correlating to the study done by Gupta et al., ${ }^{10}$ in which $22.7 \%$ of patients with ectopic pregnancies had PID. Endosalpingitis due to PID may entrap the migrating embryo, leading to ectopic implantation and peritubal adhesions, and impaired peristaltic movements may also give rise to inadequate transportation.

IUCD as a risk factor was seen in $8 \%$ of patients. IUCD prevents intrauterine pregnancies but not ovarian and tubal pregnancies. ${ }^{11}$ If a woman conceives with an IUCD in situ, the risk of a tubal pregnancy increases.

In our study, eight (66.6\%) patients presented with ruptured ectopic pregnancy, two (16.66\%) patients reported impending rupture, and only two patients came in an unruptured state with mild pain and were given methotrexate $50 \mathrm{mg} / \mathrm{m}^{2}$, a single dose. Urine for pregnancy test, serum beta human chorionic gonadotropin ( $\mathrm{hCG}$ ), and ultrasound were the diagnostic tools used to confirm the diagnosis of ectopic pregnancies.

Laparotomy was done in eight patients with ruptured ectopic pregnancies, two with impending rupture, and one with failed medical management. Unilateral salpingectomy was the mode of treatment in ruptured ectopic pregnancies. Salpingostomy was done in three patients, two with impending rupture, and one with failed medical management. One patient responded to a single dose of methotrexate $50 \mathrm{mg} / \mathrm{m}^{2}$. We avoided giving multiple doses of methotrexate, as a higher cumulative dose of methotrexate has the potential for more severe side effects. ${ }^{12}$ Methotrexate is more effective in the treatment of ectopic gestation when a quantitative serum hCG level is less than $5000 \mathrm{mIU} / \mathrm{mL}$ and there is no fetal cardiac activity detected by ultrasonography. ${ }^{8}$ Before giving methotrexate to patients with unruputured tubal pregnancies, laboratory investigation included a complete blood count, liver function tests, serum creatinine, and blood group.

Laparotomy was preferred in patients with ruptured ectopic pregnancies because during laparoscopy because of pneumoperitoneum viral particles in the surgical plume could potentially escape into the operation theater from leakage around an imperfect trocar seal and during rapid venting through trocars at the time of changing instruments, removing specimens, or desufflation at the conclusion of the operation. ${ }^{13,14}$

The commonest site of ectopic pregnancies was the ampulla (55.54\%) of the fallopian tube. The ampullary part of the tube was also commonly involved in a study conducted by Swende and Jogo. ${ }^{15}$

The recent trend in the management of ectopic pregnancies is the use of conservative surgery or medical management but unilateral salpingectomy was the treatment modality in the majority (66.6\%) of the cases in our study, as there was a delay in seeking medical advice and the patients reported a ruptured state of ectopic pregnancies. However, no maternal mortality was found in our study.

\section{Conclusion}

Our data raise serious concerns regarding the potential deleterious consequences of COVID-19 pandemic in women of reproductive age-group. It may be because accessibility to hospitals and medical advice took a back seat because of lockdown and restrictive movements during lockdown. We think that monitoring the indirect potential consequences of COVID-19 pandemic is imperative and the focus should be back to women's health and emergencies.

\section{References}

1. Youssef A, Serra C, Pilu G. Lung ultrasound in the coronavirus disease 2019 pandemic: a practical guide for obstetricians and gynecologist. Am J Obstet Gynecol 2020;223(1):128-131. DOI: 10.1016/j.ajog.2020.05.014.

2. Mullins E, Evans D, Viner RM, et al. Coronavirus in pregnancy and delivery: rapid review. Ultrasound Obstet Gynecol 2020;55(5):586592. DOI: 10.1002/uog.22014.

3. Poon LC, Yang H, Dumont S, et al. ISUOG Interim Guidance on coronavirus disease 2019 (COVID-19) during pregnancy and puerperium: information for healthcare professionals - an update. Ultrasound Obstet Gynecol 2020;55(6):848-862. DOI: 10.1002/ uog.22061.

4. Poon LC, Abramowicz JS, DallAsta A, et al. ISUOG Safety Committee Position Statement: safe performance of obstetric and gynecological scans and equipment cleaning in context of COVID-19. Ultrasound Obstet Gynecol 2020;55(5):709-712. DOI: 10.1002/uog.22027.

5. Roberton T, Carter ED, Chou VB, et al. Early estimates of the indirect effects of the COVID-19 pandemic on maternal and child mortality in low-income and middle income countries: a modelling study. Lancet Glob Health 2020;8(7):901-908. DOI: 10.1016/S2214-109X(20)30229-1.

6. Mahboob U, Mazhar SB. Management of ectopic pregnancy: a twoyear study. J Ayub Meb Coll Abbottabad 2006;18(4):34-37. https:// www.jamc.ayubmed.edu.pk/index.php/jamc/article/view/4267.

7. Barnhart KT. Clinical practice. Ectopic pregnancy. N Engl J Med 2009;361(4):379-387. DOI: 10.1056/NEJMcp0810384.

8. American College of Obstetricians and Gynecologists' Committee on Practice Bulletins-Gynecology. ACOG Practice Bulletin No. 193: Tubal ectopic pregnancy. Obstet Gynecol 2018;131(3):e91-e103. DOI: 10.1097/AOG.0000000000002560.

9. Panchal D, Vaishnav G, Solanki K. Study of management in patient with ectopic pregnancy. NatI J Integr Res Med 2011;2(3):91-93. http:// nicpd.ac.in/ojs-/index.php/njirm/article/view/1928.

10. Gupta BK, Pathania K, Jindal M, et al. Risk factors for ectopic pregnancy; a case control study in tertiary care centre. J Dent Med Sci 2014;13(3):23-27. http://www.iosrjournals.org/iosr-jdms/papers/ Vol13-issue3/Version-4/D013342327.pdf.

11. Shetty S, Shetty A. A clinical study of ectopic pregnancies in a tertiary care Hospital of Mangalore, India. Innov J Med Health Sci 2014;4(1):305-309. http://innovativejournal.in/index.php/ijmhs/ article/view/600.

12. Wellstein A, Giaccone G, Atkins MB, et al. Cytotoxic drugs. In: Bruton LL, Hilal-Dandan R, Knollmann BC, editors. Goodman and Gilman's: the pharmacological basis of therapeutics. 13th ed. New York, NY: McGraw-Hill Education; 2018. p. 1167-1202. https://accesspharmacy. mhmedical.com/content.aspx?bookid=2189\&sectionid=172486857.

13. Vigneswaran $Y$, Prachand VN, Posner MC, et al. What is the appropriate use of laparoscopy over open procedures in the current COVID-19 climate? J Gastrointest Surg 2020;24(7):1686-1691.DOI: 10.1007/ s11605-020-04592-9.

14. AAGL, COVID-19: Joint statement on minimally invasive gynecologic surgery. Available at: https://www.aagl.org/news/covid-19-joinstatement-on-minimally-invasive-gynecologic-surgery [Retrieved April 27, 2020].

15. Swende TZ, Jogo AA. Ruptured tubal pregnancy in Makurdi, North Central Nigeria. Niger J Med 2008;17(1):75-77. DOI: 10.4314/njm. v17i1.37361. 